Research Article

\title{
SWOT Analysis of China's Ceramic Industry and the Use of Computers for Scientific and Technological Innovation Research
}

\author{
Ye Tian ${ }^{1}{ }^{1}$ and Xiaobing $\mathrm{Hu} \mathbb{D}^{2}$ \\ ${ }^{1}$ Graduate School, Jingdezhen Ceramic University, Jingdezhen 333000, Jiangxi, China \\ ${ }^{2}$ Fine Art School, Anqing Normal University, Anqing 246001, Anhui, China
}

Correspondence should be addressed to Xiaobing Hu; 1976hxb@aqnu.edu.cn

Received 28 July 2021; Accepted 7 August 2021; Published 16 August 2021

Academic Editor: Punit Gupta

Copyright (c) 2021 Ye Tian and Xiaobing Hu. This is an open access article distributed under the Creative Commons Attribution License, which permits unrestricted use, distribution, and reproduction in any medium, provided the original work is properly cited.

\begin{abstract}
Chinese ceramics have a long history and have been deeply recognized by the world after centuries of changes. The current world ceramic industry is diversified. Under this background, there is a huge challenge to the development of Chinese ceramics. The update of materials, the participation of computers in ceramic design, and the demonstration of ingredients all constitute technological factors that cannot be ignored in the development of the ceramic industry. Therefore, this study uses the SWOT analysis method to analyze the development of Chinese ceramics, puts forward its advantages and disadvantages, opportunities, and threats, and under the background of advanced technology, and how to use computer software to demonstrate raw materials and color matching to make Chinese ceramics. The development achieves the goal of self-improvement and then completes the upgrade of its production process and production. Through the research of this study, it is found that the current development of China's ceramic industry should be good at using SWOT analysis, face up to its shortcomings and pressure from other ceramic production areas in the world, give full play to its advantages, maximize strengths and avoid weaknesses, and use technological innovation, combined with technical factors from other disciplines, to promote ceramic industry design and production capabilities and provide a reference for the current ceramic industry development.
\end{abstract}

\section{Introduction}

SWOT analysis is also known as situation analysis [1]; it can also be called TOWS analysis or Dawes matrix analysis. In the early 1980s, this method was mainly proposed by a professor of management at the University of San Francisco Weihrich [1]. Each letter in SWOT stands for a certain aspect of the situation. $S$ stands for strengths, W stands for weaknesses, $\mathrm{O}$ stands for opportunities, and $\mathrm{T}$ stands for threats. $\mathrm{S}$ and $\mathrm{W}$ belong to internal factors, while $\mathrm{O}$ and $\mathrm{T}$ belong to external factors. In the context of the rapid development of international ceramics, SWOT has been applied to the development analysis of the ceramic industry in recent years. Some studies focus on the development of regional ceramics $[2,3]$. Some research studies use the SWOT analysis method; this study analyzes the Jingdezhen ceramic culture creative industry under the environment of existing market competition advantages, disadvantages, opportunities, and threats of development, and based on this, put forward the Jingdezhen ceramic culture creative industry core competitiveness promotion strategy [4]; in some studies by the SWOT analysis of the ceramic export competitiveness [5], the export of ceramics industry is systematically analyzed. These studies all take SWOT analysis as the research method from different angles to explore the development of the ceramics industry. This study used the SWOT analysis method from a macro perspective to explore China's ceramic industry development in the present situation and the advantages and disadvantages, and in the context of science and technology innovation, analysis using a computer to carry on the technological innovation, show the advantages such as material, color is tie-in, to improve the efficiency of 
ceramic design and production, and to provide a reference for the ceramic production and design.

\section{Advantages and Disadvantages of the Development of Chinese Ceramics}

2.1. Advantages. The advantages shown by China's ceramic industry focus on the following aspects:

\subsubsection{Has a Long History of Ceramic Culture.} Time-honored ceramics belong to the treasure of Chinese civilization. The cultural development of Chinese ceramics has a very long history, extensive and profound. The original celadon had appeared in China over 3,000 years, during the Shang Dynasty (Figure 1). Every different historical stage of ceramics in China shows its completely different artistic style and expression. Chinese ceramic culture has developed into the most core competitive advantage of Chinese ceramics.

2.1.2. Production Is Large Scale and Low Cost. At present, China has become the world's largest ceramic production country, accounting for more than half of the world's total ceramic production output. After a long-term accumulation, China's ceramic industry has formed a very strong scale effect and has great potential to be explored. At the same time, because the labor cost of China's ceramic industry is relatively low, the raw materials are also of high quality and cheap price, and they are very abundant, which has a strong cost advantage; these provide strong raw material support for the development of the ceramic industry.

\subsubsection{Domestic Market Has Great Development Potential.} The advantage of China's ceramic industry development also lies in a huge domestic market. According to the Seventh National Census Bulletin of 2020 (Number 8) [6], China has a total population of more than 1.4 billion and has a new population of about 20 million per year. In the long run, the investment in real estate development will certainly continue to grow. In recent years, the annual urban real estate development investment is more than 300 billion yuan, the annual completion area of housing has reached 1.5 billion square meters, and the residents' construction decoration cost has reached the annual scale of more than 400 billion yuan. In addition, some big cities in China have also begun to stipulate that the sale of rough houses will not be allowed, so the real estate developers will surely become another very important buyer of construction pottery products. With the rapid improvement of people's living conditions, the need for construction ceramics will certainly remain at a relatively high level. In addition, with the gradual increase of the Chinese government's support for the great development of the west, the marketing of the ceramic market has gradually developed rapidly from the east to the west, the capacity of the domestic ceramic market has undergone qualitative changes, and has gradually developed into one of the most growth potential markets in the domestic building materials industry. In the foreseeable future, in the next 10 years, or

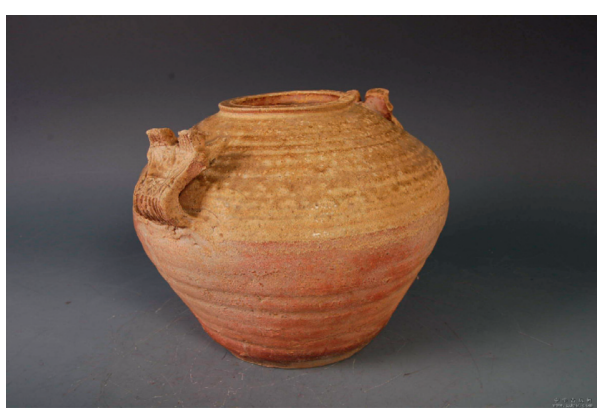

Figure 1: Primitive celadon.

even 20 years, the strong domestic market demand will still maintain the rapid and stable development of China's construction pottery industry.

\subsection{Disadvantages}

2.2.1. Development and Design Lacks Internal Motivation. Compared with the international advanced ceramics, the development and design level of domestic ceramics is far behind. Most ceramic enterprises in China lack the sense of innovation, invest very little investment in design, and have an insufficient investment in research and development. As a result, Chinese ceramic products show three characteristics of homogeneity, trend, and imitation. Ceramic products lack innovation and style; design and color varieties change slow, single style. No matter in the variety, quality, specifications, model, color is very close, and what products are good to sell, used to imitation and cloning, this makes it difficult for ceramic products to occupy not only a strong share in the international market but also cause ceramic products market backlog.

2.2.2. Lack of Standardization of Process and Technology. Foreign ceramic industry in the overall industrial technology, its automation, and intelligence degree is relatively high. It uses more modern processes and technology. Ceramic production generally adopts a professional division of labor, with a standardized, commercialized raw material base, and professional auxiliary material suppliers. Although China's ceramic industry has greatly improved the level of process equipment through the introduction, digestion, and absorption of foreign advanced equipment, most enterprises are still mainly semimechanized equipment. Many ceramic enterprises, especially nonceramic cluster area enterprises, lack standardization and the supply of specialized raw materials and auxiliary materials, resulting in great product quality fluctuations and difficulty in meeting the requirements of the high-grade ceramic production process. In addition, there is also a huge gap in the production of molding and mold materials and machinery and equipment manufacturing industry serving the ceramic industry, which all restrict the improvement of product quality and competitiveness of the industry [7]. 
2.2.3. The Quality of the Products Is Mixed. Most Chinese enterprises are affected by production, processing, technical personnel, quality control, and other factors. Product quality and grade are low, and the overall quality level is to be improved. The internal quality and appearance quality are still great compared with well-known foreign ceramic brands. In addition, in recent years, due to low industry thresholds that have launched various ceramic lines, market expansion leads to disorderly competition between brands and price reduction, and it is difficult to effectively guarantee the ceramic quality.

\subsubsection{Corporate Management Lacks a Strong International} Concept. Many domestic ceramic enterprises adopt an extensive management mode, and the international modern enterprises, mainly manifested as lack of advanced management ideas, methods, and means, low strategic decisionmaking level, weak management foundation, low information technology management level, and lack of management personnel familiar with international trade and market operation rules; operation and management mechanism does not adapt to the requirements of market competition and lack of international marketing experience [8].

\section{Opportunities and Threats}

\subsection{Opportunity}

3.1.1. Opportunities Brought about by China's Rapid Economic Development. This opportunity is mainly manifested in the following three aspects. First of all, the development level of urbanization is constantly improving. With the further implementation of the "agriculture, rural areas and farmers" policy, the farmers have also been further improved at the residential level, and the amount of ceramic tile use will be very huge in the future. In the past, in the countryside, in this piece, the amount of ceramic use is very few, mainly because the economy of many places is not too rich; when building a house that stick ceramic tile is very little, after farmers have money, the area that stick ceramic tile will gradually increase.

Second, the urbanization development level of our country is relatively low, with only $36 \%$. A very important measure of the current country is to vigorously promote the process of urbanization development. The acceleration of the urbanization development process will further and quickly improve our infrastructure construction speed, and the improvement of the infrastructure construction speed will usually further drive the rapid development of the real estate industry. This will also further drive the rapid development of the building materials industry because this is synchronous development; therefore, the demand for building materials in this respect will also appear under the role of continuous growth.

Finally, the international market provides a very good opportunity, and the current number of ceramic exports is increasing by more than $50 \%$ per year. These factors together create a very good environment for the development of the building materials industry.

3.1.2. Opportunities Brought by WTO Entry. After joining the WTO, the development of Chinese ceramic enterprises mainly from domestic market to international market adjust the industrial structure according to the needs of the international market, participate in the international division of labor and collaboration [9] through external competitive mechanisms and the introduction of advanced technologies, and eliminate backward products and equipment, so as to further realize the sustainability of the ceramic industry development. After joining the WTO, China's ceramic industry can further expand its exports, while driving domestic economic growth, with the transparency of the law and the further realization of the national treatment. The investment environment was further improved, forming a new advantage of attracting foreign investment. Then, it will open a very broad development channel for foreign businessmen to invest in the ceramic industry and realize transnational operation. After joining the WTO, ask for more ceramic companies to operate under internationally recognized business rules, establish a modern enterprise system adapted to the market economy competition, further improve the management system and operation mechanism of enterprises, and vigorously promote the improvement of business efficiency and the rapid improvement of international competitiveness.

\subsection{Existing Threats}

3.2.1. The Threat of World Ceramic Power and Well-Known Foreign Ceramic Enterprises. Some global ceramic powers have a large number of large-scale well-known enterprises with strong competitiveness. These enterprises all have very strong capital, very perfect management experience and marketing strategies, and are at the high-end level in the global value chain. On the contrary, China's ceramic industry has a low position in the world, is at the low end of the value chain, and is also at a disadvantage in the process of very fierce international market competition in the future. In addition, with the gradual opening of the Chinese market and the further reduction of tariffs, well-known foreign ceramic enterprises have also further seized the domestic ceramic market, thus increasing the impact and threat to the domestic ceramic market.

3.2.2. Antidumping Threat. Antidumping mainly refers to a boycott of the dumping of foreign goods in their domestic markets. Because China's ceramic products have a very strong price competitive advantage, with the rapid development of the current world economy, the export growth is relatively fast and the export market is very concentrated, leading to the intensified conflict between China's export products and importing countries. At the same time, some enterprises lack deep understanding and communication of the international community, and many countries do not 
understand China's market economy reform and the development process, to China's market economy development situation, leading to some countries for China has very big trade discrimination, "China threat theory" and "nonmarket economy" black hat are very deeply rooted in these countries, so that China's ceramic enterprises were subjected for extensive foreign antidumping investigation. Not only the developed economies but even emerging economies in daily ceramics, especially in BRICS countries and China, are gradually increasing. In recent years, the European Union, the United States, India, Brazil, and other countries have formed an antidumping investigation on China's ceramic industry.

\subsubsection{Threats of Technical Trade Barriers. Technical barriers} to trade (TBT) mainly refers to the trade barriers formed by some mandatory and nonmandatory technical regulations and standards formulated by a country or regional organization on the grounds of maintaining its basic safety, ensuring the health and safety of humans and animals and plants, protecting the environment, preventing fraud, and ensuring the quality of products. Technical trade barriers are another obstacle to the export of Chinese ceramic products. To protect the interests of their ceramic manufacturers from damage, many countries, with their own technical and economic advantages, prevent China from exporting ceramics to them by formulating a variety of more demanding technical barriers. These technical barriers include standards and technical regulations, technical certification systems, conformity assessment, labeling and packaging, green technology, and e-commerce technology. In the face of technical trade barriers, Chinese ceramic enterprises have exposed incomplete information mastery, immature technical ability, and high copying costs. In the current situation of the ceramic industry, it is very difficult for some Chinese ceramic enterprises to cross these barriers, cause a few obstacles to the export of China's ceramic, and greatly hinder China's ceramics to participate in the international market competition [7].

\section{Scientific and Technological Innovation, Optimization, and Upgrading of Contemporary Ceramic Art}

\subsection{Use of the Polymer to Enhance the Clay Materials}

4.1.1. Cured the Clay Material with Cyanoacrylate. The basic operating idea is to dry the prepared clay billet and soak it in the solution of $\alpha$-acetyl cyanoacrylate. Because the composition of $\alpha$-cyanoacrylate adhesive is mainly $\alpha$-ethyl cyanoacrylate, it contains only a small amount of thickener and stabilizer, can play a rapid curing role, can be combined under the catalytic action of trace water in the air, and can quickly cure and bond clay, which can form a very solid cold ceramic.

\subsubsection{Cured Clay Materials by the Radiation Method}

(1) Idea. After drying the prepared clay billet, it is soaked with a methyl methacrylate monomer solution and then irradiated with a ${ }^{60} \mathrm{Co}$ radiation source, thus forming the polymer effect, forming a polymethyl methacrylate (also known as organic glass), further forming a very solid cold ceramic.

Among them, two radiation methods are involved, namely, radiation crosslinking and radiation polymerization. Radiation crosslinking mainly connects two polymer chains in some way, and the net effect of crosslinking is the increasing molecular weight until the $3 \mathrm{D}$ network structure is formed, so once the polymer is aligned, it makes the clay material very difficult to dissolve and melt.

Radiation polymerization mainly uses radiation to stimulate the monomer, causing polymerization. The gas, solid, liquid, and emulsion polymerization of acrylic monomer can be realized by radiation. High polymer materials prepared by the radiation method are usually characterized by high molecular weight and high purity.

(2) Relevant Production Steps. First, use the clay maker type and second, the prepared device type Yin dry, so that it is gradually dehydrated. Again, the dewatered clay billet is put into a methyl methacrylate monomer solution to be fully absorbed. Finally, the clay billet absorbing the methyl methacrylate monomer is irradiated at a ${ }^{60} \mathrm{Co}$ radiation source for the polymerization reaction to occur.

The main advantage of producing cold pottery by the radiation method is that without high temperature, the clay can well preserve the color and texture without burning.

\subsection{Computer-Aided Design of Ceramic Color Matching}

4.2.1. Methodology. Ceramic glaze patterns need to change at a high temperature of $1000^{\circ} \mathrm{C}$ or higher, which usually makes it difficult for artists to intuitively design the glaze color of ceramic art. The idea here is mainly based on the glazing code, computer-aided design; the first step should be the direct pattern design in the computer, convert the design pattern to the coded glaze coloring scheme, and finally, the glaze drawing on the ceramic billet. The contents shown in Figures 2 and 3 and Tables 1 and 2 are derived from the introduction of the ceramic products by Ferro [10].

\subsubsection{Related Cases}

(1) Rob Kessler Ceramic Art Design. Wolfgang Stuppy, a renowned botanist in Keyou District, has made a very careful analysis of the sexual reproductive complexity of plants with the visual artist Rob Kesscler [11]. Rob Kesscler microphotographs of wild pollen in the Royal Wild Botanical Gardens, with many wonderful photographs, striving to reproduce the image of the natural world, plants, and flowers migrated to all aspects of society.

Rob Kessler scanned the wild pollen microphotos into a transparent laser film, before printing the painted paper on screen printing. After drying, the printed pattern coating paper is soaked in water so that the pattern can fall off the paper base and be transferred onto the blank of the product and burned between $750^{\circ} \mathrm{C}$ and $900^{\circ} \mathrm{C}$ (Figure 4). 


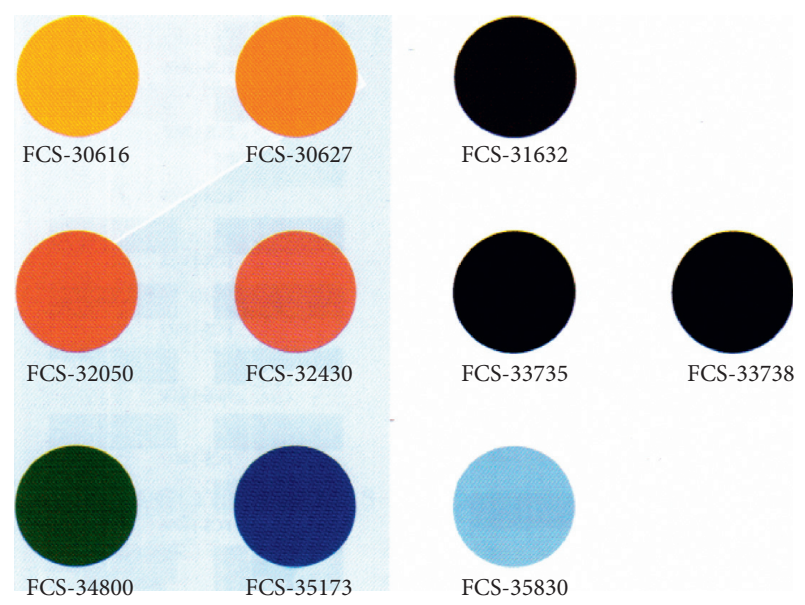

Figure 2: Billet body color chromatography.

In addition to this, digital technology can also bring great convenience and style breakthrough to pattern design.

(2) Blue and White Issued by Adobe Software Design. "Blue and White" (2007 Adobe China Shall We Dance Digital Art Competition Gold Award, created by Fan Yongguang) is a blue and white porcelain plate (Figure 5). The traditional decoration and transparent colorfully show the Chinese blue and white porcelain is very delicate and smooth. On careful observation, the above patterns are arranged by various tool icons commonly used in Adobe software. Thus, the author took great effort and made full use of the time to design and make the porcelain plate.

The overall design of the work is very in line with the relevant requirements of "Chinese wind," in the very representative Chinese blue and white porcelain as its main carrier at the same time can be the Adobe elements that are very perfectly integrated into them, and not only fully embodies the beauty of Chinese traditional culture but also shows the infinite charm brought by the digital tools. This also belongs to the Chinese culture where modern digital art is gradually valued and is very closely combined with Chinese culture into an excellent external form of expression.

(3) Cultural and Creative Products of Local Opera Elements. "Zodiac Huangmei-Zodiac Dog," [12] a glazed cultural and creative porcelain plate (Figure 6), is one of the twelve zodiac Huangmei series; the combination of traditional decoration and animation image fully highlights the vividness of the visual image of the product. The above pattern is designed with Adobe image-making software. The author spent a lot of time creating, examining the local drama culture, refining the visual image with a sense of design, and designing and producing a series of cultural and creative works in the form of the twelfth Chinese zodiac.

The overall design of the work is very in line with the relevant requirements of "Chinese style," and using the very representative Chinese ceramic as the main carrier, the cultural elements of Huangmei Opera are perfectly integrated into it. It not only fully embodies the beauty of
Chinese drama culture but also shows the artistic charm brought by digital media tools.

\subsection{Mathematical Thinking in Ceramic Art}

4.3.1. Mathematical Configurations in Ceramic Art. In the creation of ceramic art, using relevant theories, theorems, laws, logical thinking methods, and techniques, analyze, describe, process, and check the design methods of ceramic design processes and objects. You can use various geometric curves and geometric graphs to divide and combine ellipticals, squares, and triangles by certain rules. It can be combined into various monomers and matching ceramic shapes.

The geometric structure ceramic artworks designed by Mr. Han Meilin show a simple, concise, and lively feature, full of joy. He cut and combined different circles and arcs, producing a very rational and very simple body language, full of philosophical thinking (Figure 7).

Professor Zhang Jingjing's works mainly extend some curves in mathematics into curved surfaces and then integrated the brittle characteristics of ceramics and the soft mathematical curves (Figure 8).

\subsubsection{Topological Composition in Ceramic Art. Topology is} an independent branch of mathematics formed in the 19th century, studying the nature of geometry based on continuous deformation. In topology, each size and shape can be bent and changed. Because a large number of natural phenomena have typical continuity, many practical things can be transformed into the topology. Explain the collection of space for mastering the different functional relations between spaces. Figure 9 shows the topological ceramic works created by Mr. Bai Ming. He can play the simple elements of nature into the ultimate elegance. His art has vitality and is constructive at the same time. Ceramics has been a transformative sublimation here as said by Bai Ming. Some of his works include creative cracks, folds, and broken lines, from which his thinking about history and the passage of time are seen [13].

\section{Optimization and Upgrading of Ceramic Products}

For a long time, China's ceramic industry is mainly engaged in low-grade products and is currently in the development stage from quantity growth to quality and efficiency. The focus should be in the future on improving product quality and grade. The improvement of the product grade will lead to a corresponding increase in the sales price, resulting in a profit increase, which will moderately increase the product cost, which also means that the company can use clean and pollution-free fuel to implement technological transformation and equipment upgrading. Purchasing and utilization of energy conservation and environmental protection equipment to improve the level of energy conservation and emission reduction can promote the improvement of product grade and finally realize a virtuous cycle. Improving 

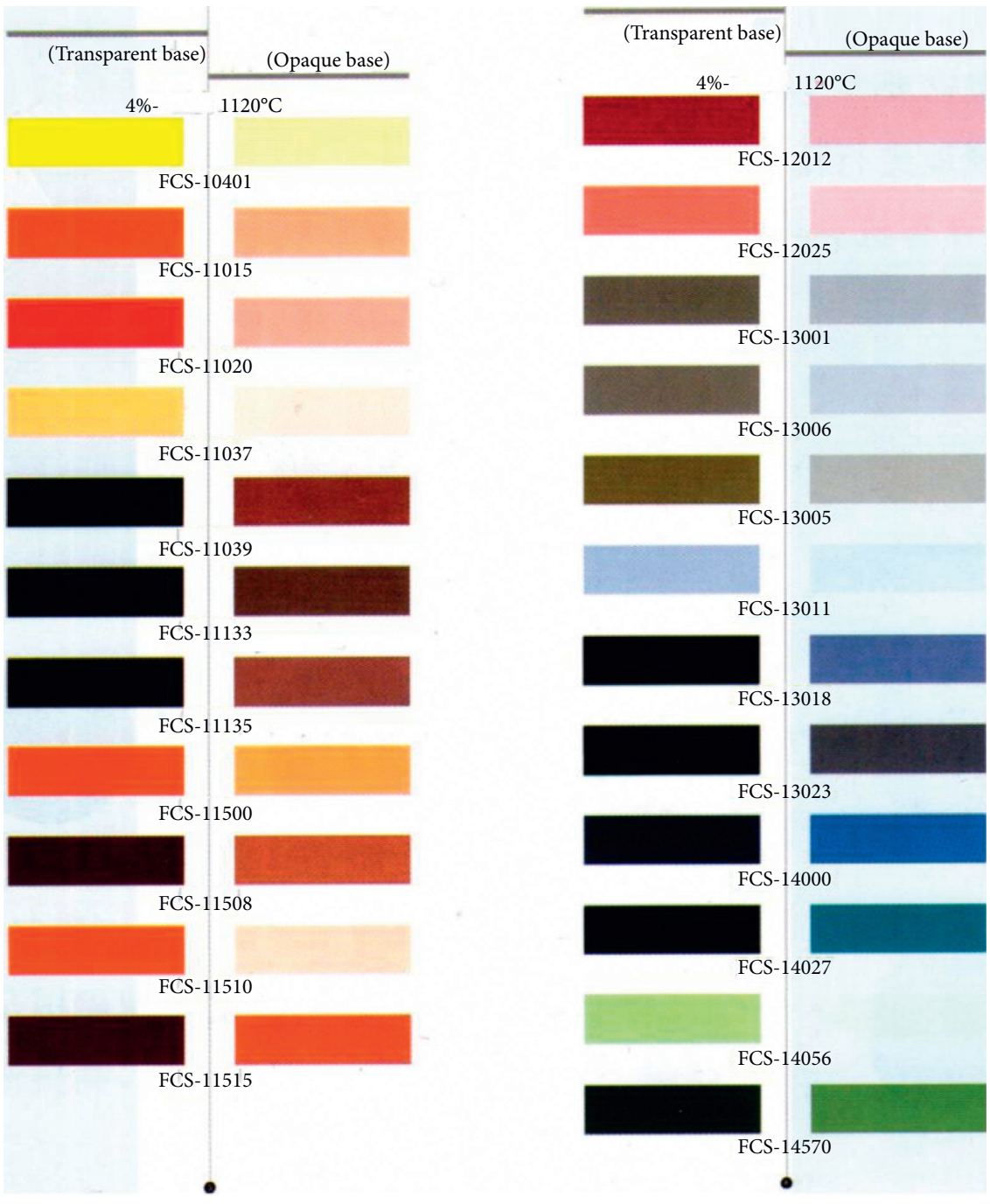

Figure 3: Chromatography for glaze material.

TABLE 1: Biomaterial.

\begin{tabular}{lcccc}
\hline Code & Description & Composition & Maximum temperature $\left({ }^{\circ} \mathrm{C}\right)$ & Residue \#400 \\
\hline FCS-30616 & Buff & Ti-Sb-Cr & 1300 & 1300 \\
FCS-30627 & Buff & Ti-Sb-Cr & 1300 & $<1$ \\
FCS-31632 & Brown & Fe-Cr-Al-Zn & 1300 & $<1$ \\
FCS-32050 & Red & Yb-Ca-Cr & Mn-Al & 1300 \\
FCS-32430 & Pink & Fe-Cr & 1300 & $<1$ \\
FCS-33735 & Cobalt-free black & Fe-Cr-V & 1300 & 1300 \\
FCS-33738 & Cobalt black & Cr-Al & 1300 & $<1$ \\
FCS-34800 & Green & Co-Al & 1300 & $<1$ \\
FCS-35173 & Cobalt blue & V-Zr & $<1$ \\
FCS-35830 & Turquoise blue & &
\end{tabular}

product quality and grade requires ceramic industry enterprises to actively develop new products and vigorously develop ceramic products with high technical content, good economic efficiency, low resource consumption, and small environmental pollution. During the 13th Five-Year Plan period, China should develop more environmental-conscious sanitary ceramic products, further increase its proportion, research, and development of new products with high technical content and antibacterial, self-cleaning, light storage, conductivity, noise reduction, filtration, health, insulation, and achieve industrialization. We should advocate the reduction of resources, solve the major technical and equipment problems in technology, technology, equipment, specification, and application due to the reduction of thickness, and vigorously promote the thinning process of ceramic bricks. Developing and promoting the application 
TABLE 2: Glazing colors.

\begin{tabular}{|c|c|c|c|c|}
\hline Code & Description & Composition & Maximum temperature $\left({ }^{\circ} \mathrm{C}\right)$ & Residue $\# 400$ \\
\hline FCS-10401 & Yellow & $\mathrm{Zr}-\mathrm{Pr}-\mathrm{Si}$ & 1230 & $<0.4$ \\
\hline FCS-11015 & Coral & $\mathrm{Zr}-\mathrm{Fe}-\mathrm{Si}$ & 1230 & $<0.4$ \\
\hline FCS-11020 & Coral & $\mathrm{Zr}-\mathrm{Fe}-\mathrm{Si}$ & 1230 & $<0.4$ \\
\hline FCS-11037 & Peach & $\mathrm{Zr}-\mathrm{Fe}-\mathrm{Pr}-\mathrm{Si}$ & 1230 & $<0.4$ \\
\hline FCS-11039 & Chocolate brown & $\mathrm{Fe}-\mathrm{Cr}-\mathrm{Zn}$ & 1230 & $<0.4$ \\
\hline FCS-11133 & Dark brown & $\mathrm{Fe}-\mathrm{Cr}-\mathrm{Ni}-\mathrm{Zn}$ & 1230 & $<0.4$ \\
\hline FCS-11135 & Dark brown & $\mathrm{Fe}-\mathrm{Cr}-\mathrm{Ni}-\mathrm{Zn}$ & 1230 & $<0.4$ \\
\hline FCS- 11500 & Golden brown & $\mathrm{Fe}-\mathrm{Cr}-\mathrm{Zn}-\mathrm{Al}$ & 1230 & $<0.4$ \\
\hline FCS-11508 & Dark brown & $\mathrm{Fe}-\mathrm{Cr}-\mathrm{Zn}-\mathrm{Al}$ & 1230 & $<0.4$ \\
\hline FCS- 11510 & Brown & $\mathrm{Fe}-\mathrm{Cr}-\mathrm{Al}-\mathrm{Zn}$ & 1230 & $<0.4$ \\
\hline FCS-11515 & Red brown & $\mathrm{Fe}-\mathrm{Cr}-\mathrm{Al}-\mathrm{Zn}$ & 1230 & $<0.4$ \\
\hline FCS-12012 & Maroon & $\mathrm{Sn}-\mathrm{Cr}-\mathrm{Ca}-\mathrm{Si}$ & 1230 & $<0.4$ \\
\hline FCS-12025 & Light maroon & Sn-Cr-Ca-Si & 1230 & $<0.4$ \\
\hline FCS-13001 & Nickel grey & $\mathrm{Co}-\mathrm{Ni}$ & 1230 & $<0.4$ \\
\hline FCS-13005 & Dark grey & Co-Mn & 1230 & $<0.4$ \\
\hline FCS-13006 & Light grey & $\mathrm{Fe}-\mathrm{Cr}-\mathrm{Mn}-\mathrm{Ni}$ & 1230 & $<0.4$ \\
\hline FCS-13011 & Tin grey & $\mathrm{Sn}-\mathrm{Sb}$ & 1230 & $<0.4$ \\
\hline FCS-13018 & Cobalt black & $\mathrm{Fe}-\mathrm{Cr}-\mathrm{Co}-\mathrm{Mn}$ & 1230 & $<0.4$ \\
\hline FCS-13023 & Cobalt-free black & $\mathrm{Fe}-\mathrm{Cr}$ & 1230 & $<0.4$ \\
\hline FCS-14000 & Peacock blue & $\mathrm{Co}-\mathrm{Al}-\mathrm{Cr}$ & 1230 & $<0.4$ \\
\hline FCS-14027 & Peacock green & Cr-Co-Zn & 1230 & $<0.4$ \\
\hline FCS-14056 & Apple green & Zr-Si-Pr-V & 1230 & $<0.4$ \\
\hline FCS- 14570 & Chrome green & $\mathrm{Cr}-\mathrm{Al}$ & 1230 & $<0.4$ \\
\hline FCS-15063 & Blue & Co-Al-Zn & 1230 & $<0.4$ \\
\hline FCS-15090 & Turquoise & $\mathrm{Zr}-\mathrm{Si}-\mathrm{V}$ & 1230 & $<0.4$ \\
\hline FCS-15500 & Cobalt blue & $\mathrm{Co}-\mathrm{Si}$ & 1230 & $<0.4$ \\
\hline 4FCS-16035 & Yellow & $\mathrm{S}-\mathrm{Se}-\mathrm{Zr}-\mathrm{Si}-\mathrm{Cd}$ & 1230 & $<0.4$ \\
\hline FCS-16037 & Red & Zr-Cd-Se-Si & 1230 & $<0.4$ \\
\hline FCS- 16038 & Orange & $\mathrm{Zr}-\mathrm{Cd}-\mathrm{Se}-\mathrm{Si}$ & 1230 & $<0.4$ \\
\hline
\end{tabular}

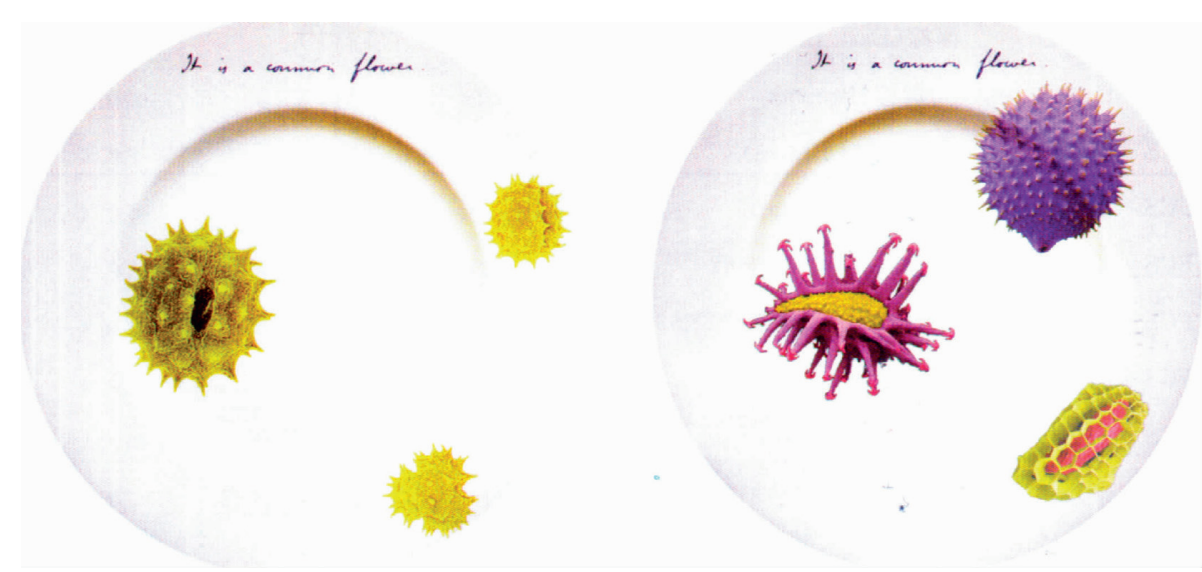

Figure 4: Rob Kessler ceramic art.

of aquatic products and accelerating the lightweight of products, for large and overweight toilets with luxury characteristics and various vertical urinals, should reduce production as much as possible.

The ceramic industry should actively develop and promote new technologies and new equipment for energy conservation and emission reduction. According to the "13th Five-Year Plan" Science and Technology Development Plan of Construction Materials Industry issued by China Federation of Construction Materials Industry [14], during the 13th Five-Year Plan period, key technologies for the development and application of Chinese building sanitary ceramics include supporting technologies for the production and application of thin building tiles (boards), continuous ball grinding process technology, new dry legal powder technology and complete set of equipment technology, energy-efficient multilayer roller dryer, new high-efficient coal gasification (self) purification equipment, ceramic decoration, spray drawing and printing technical equipment, laser printing technology equipment, new automatic ceramic tile selection and packaging technology, powder standardization and functional inkjet inks, production and 

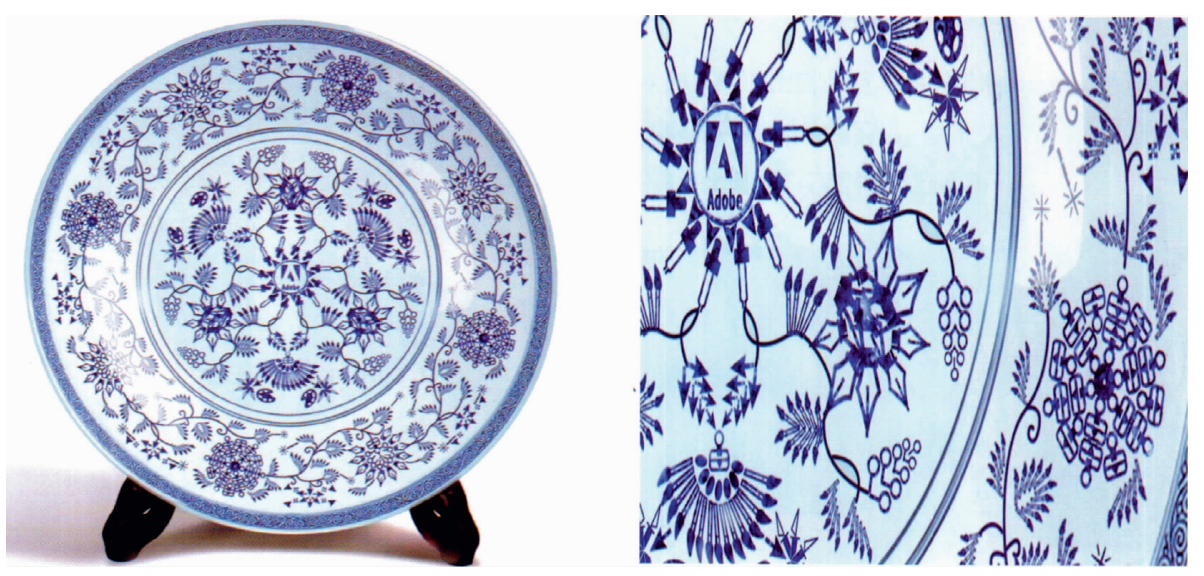

Figure 5: "Blue and white" ornamentation designed by computer.

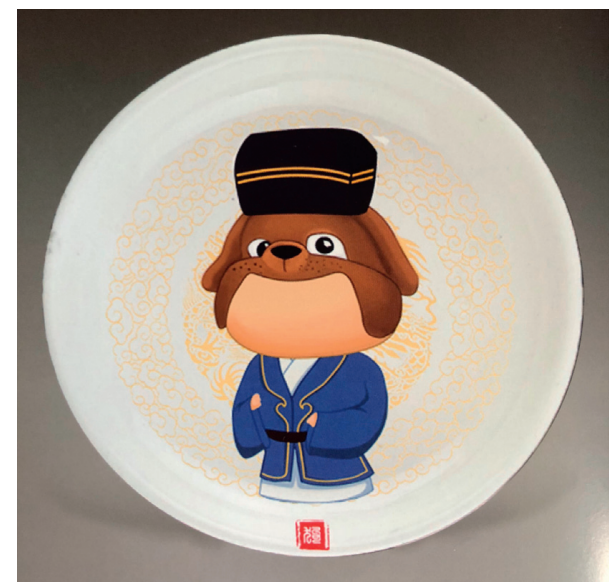

FIgURe 6: Zodiac dog.

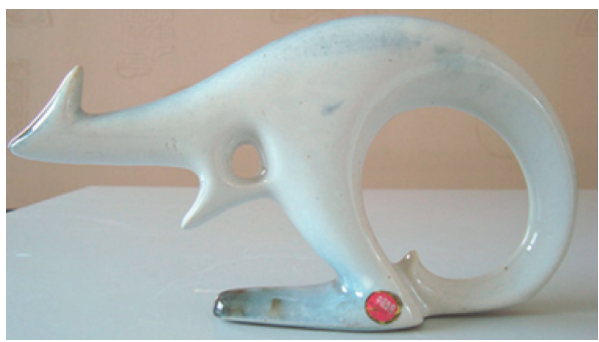

Figure 7: Works “kangaroo” by Mr. Han Meilin.

application of supporting technology for lightweight watersaving and sanitary ceramics, low-pressure rapid drainage forming technology of sanitary ceramics, high-pressure forming technology, intelligent production technology and complete equipment of sanitary ceramics (including robot glaze technology with self-learning function, initialization of the sanitary ceramic model, 3D additive printing technology, sanitary ceramic grouting robot, sanitary ceramic billet robot, sanitary ceramic kiln robot, sanitary ceramic intelligent, and efficient drying system), model development of CNC machining technology, new antibacterial and selfcleaning glaze manufacturing technology, improving the intelligent and healthy use of sanitary ceramics, developing

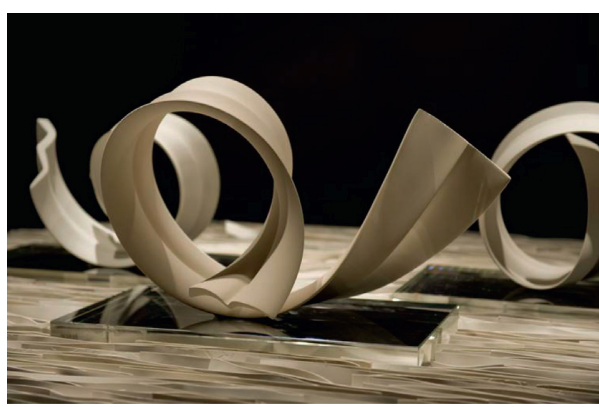

Figure 8: Spring up.

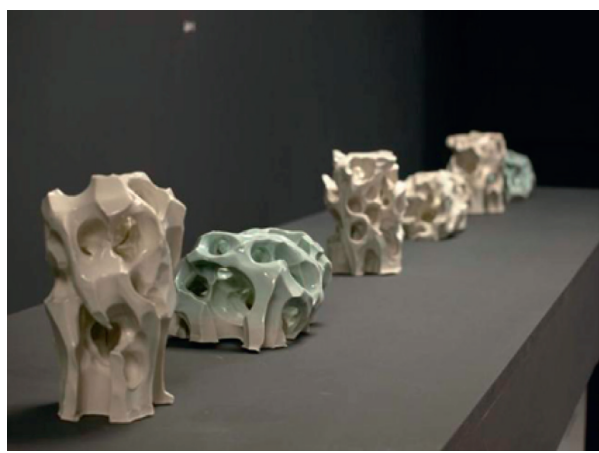

Figure 9: Taihu Lake Stone.

the application of low-grade raw materials and new waste products, accurate automatic ingredient technology of raw material standardization and flexibility, and raw material online monitoring and correction system. Wide-body energy-saving kiln, low temperature burning technology, waste heat utilization technology, robot application technology, automatic storage, and transfer production line, intelligent three-dimensional storage technology, efficient dust removal, desulfurization, defluorine technology and equipment, creative and other building health ceramic product technology, and manufacturing technology, are to develop functional new materials suitable for life decoration (sound insulation, sterilization, and fresh air). Especially in the postepidemic era, we advocate the concept of green ceramic design and production and make more products that are in 
harmony with human and natural development to benefit the global ecological development.

\section{Conclusion}

At present, the world porcelain pattern has undergone great changes. Under this background, China, as a traditional porcelain country, has both opportunities and threats, as well as advantages and disadvantages. Only by adhering to scientific and technological innovation as the leading role, promoting industrial optimization and upgrading, and creating green ceramic industry blocks, China's ceramic industry can achieve healthy and proud development. Based on SWOT analysis, this study analyzes the opportunities and disadvantages of China's ceramic industry development, challenges, and opportunities that coexist in the background, analyzes how to use scientific and technological innovation, with the help of interdisciplinary technology, better and stronger development, and hopes to provide theoretical reference for the current ceramic design and production.

\section{Data Availability}

The data supporting this study cannot be shared as no datasets were generated or analyzed during the current study.

\section{Conflicts of Interest}

The authors declare that they have no conflicts of interest.

\section{Acknowledgments}

The authors acknowledge the 2021 University Discipline (Professional) Top Talent Academic Fund Project (gxbjZD2021005).

\section{References}

[1] H. Weihrich, Management: A Global Perspective, Economic Science Press, Beijing, China, 11th edition, 2005.

[2] H. Yao and Q. Gu, "SWOT analysis of the competitiveness of Dehua ceramics industry and its improvement countermeasures," Journal of Minnan Normal University (Philosophy and Social Sciences Edition), vol. 7, no. 3, pp. 96-101, 2012.

[3] S. Li, "SWOT analysis and countermeasures of Zibo ceramic exports," Northern Economy, vol. 7, no. 11, pp. 27-28, 2007.

[4] J. Huang, H. Haiwang, W. Jiang et al., "SWOT analysis and countermeasures of the core competitiveness of Jingdezhen ceramics cultural creative industry," Science and Technology Information, vol. 32, no. 6, p. 2, 2012.

[5] H. Zhang, "SWOT analysis of Zibo ceramics export competitiveness," Ceramics, vol. 314, no. 4, pp. 17-18, 2013.

[6] T. Tao, "Consumption trends from the seventh census data," Knowledge-Economy, vol. 50, no. 6, p. 4, 2021.

[7] G. Li, "Ten gaps alert the Chinese ceramic industry," Modern Technology Ceramics, no. 3, pp. 44-46, 2008.

[8] Y. Huang, "Research on the international competitiveness of China ceramic industry," Economic and Trade Practice, no. 13, pp. 42-43, 2016.
[9] X. Zhang and X. Zheng, "Research progress in low-temperature ceramic ceramics," Micro-Nanoelectronic Technology, vol. 56, no. 10, pp. 32-40, 2019.

[10] W. Stape, R. Keseller, W. Stuppy et al., The Miracle of the Plant Kingdom: The Mystery of the Fruit, People's Post \& Telecommunications Press, Beijing, China, 2015.

[11] X. Hu and Y. Zhang, "Research on the development and visual image of opera culture creative products," Journal of Visual Art and Design, vol. 12, no. 2, pp. 144-156, 2021.

[12] Y. Li and S. Zou, "Strategic choice for improving the international competitiveness of China's ceramic industry after WTO," University of South China: Social Sciences, vol. 3, no. 1, pp. 44-49, 2002.

[13] H. Chen, "“The country of-Bai" appeared at Beijing Minsheng modern museum," Chinese Poamist, no. 2, pp. 37-40, 2017.

[14] Anonymous, "Construction materials industry 13th five-year plan science and technology development plan," Commercial Concrete, no. 7, pp. 23-31, 2016. 